\title{
Memorias del después: hacia una hermenéutica del testimonio de prisión política ${ }^{1}$
}

\author{
Memories of the after: \\ towards a hermeneutics of testimony in political prison
}

\author{
SANDRA NAVARRETE BARRÍA \\ Universidad de Santiago de Chile, Instituto de Estudios Avanzados. \\ Correo electrónico: sandra.navarrete.b@usach.cl
}

El objetivo de este artículo es explorar en torno a las fronteras interpretativas del testimonio en su dimensión textual. Específicamente, nos interesa indagar en la importancia de las formas narrativas del testimonio para el significado que adquiere el mismo, entendido este no sólo como parte de un proceso de la memoria social, sino que, además, como un texto que puede desarrollar intenciones estéticas precisas. En este sentido, nos preguntamos: ¿¿Se pueden interpretar los testimonios? ¿Cómo influye la dimensión formal en su significado? ¿Cuáles son los alcances de un análisis hermenéutico en la comprensión de un testimonio de prisión política? Para ello, trabajaremos con dos testimonios argentinos, Una sola muerte numerosa (1997) de Nora Strejilevich y Sueños sobrevivientes de una montonera (2000) de Susana Jorgelina Ramus. En estos textos podemos identificar formas narrativas propias de la tradición literaria, las que funcionan no solo como marco estético para la representación de la experiencia traumática, sino que también como soporte para el significado mismo de lo rememorado.

Palabras clave: testimonio, memoria, formas narrativas, hermenéutica.

The aim of this article is to explore the boundaries of the testimony in its textual dimensions based on a hermeneutic framework. Particularly, the article reviews how important is the narrative style of the testimony in its meaning if we consider the aesthetic level as a valid piece to this kind of texts. Research questions include the possibility of the interpretation of testimonies of political prison; how relevant is the narrative style of the testimony in its meaning and what is the role of an hermeneutic approach in this field. The work analyze two testimonies from Argentina- Nora Strejilevich's "Una sola noche numerosa" (1997) and Susana Jorgelina Ramus's "Sueńos sobrevivientes de una montonera" (2000). The analysis results reveals that there are narratives styles from the literary tradition

\footnotetext{
${ }^{1}$ Este artículo forma parte del proyecto de investigación Fondecyt Regular № 1161551 "Formas narrativas del testimonio: relatos de prisión política en Chile, Argentina, Brasil y Uruguay".
} 
that operates in these testimonies not only as an aesthetic frame from the traumatic experience but also as a bracket for the meaning of what is remembered.

Key words: testimony, memory, narrative form, hermeneutics.

\section{LA VERDAD COMO UN HECHO DE INTERPRETACIÓN: EL ROL DEL TESTIMONIO EN LA CONSTRUCCIÓN DEL DISCURSO HISTÓRICO}

El testimonio y el testigo son el indicio de una falla y un resto, el intento (tal vez desesperado) de inscribir el propio cuerpo en relación con todo lo que existe

(Link 2008: 118).

En su ensayo Frente al limite (1993), Tzvetan Todorov examina las condiciones de un gobierno totalitario amparado en sistemas de represión, como los campos de concentración nazi o los gulag soviéticos. Aquí destaca el papel fundamental que desempeñaba la información de lo que ocurría realmente en estos lugares para el establecimiento del poder represor, explicando que el cuidado de esta información era la base de la mantención del totalitarismo, del mismo modo que el acceso a dicho conocimiento era la principal arma contra el poder. "Se sabe hasta qué punto los nazis fueron meticulosos en el mantenimiento del secreto relativo a la "solución final", cuán sistemáticamente trataron de destruir las huellas de sus actos. Los regímenes comunistas, por su parte, fundaron toda su existencia sobre la imposibilidad para la población de tener acceso a una información libre" (2009: 261). Asimismo, existe constancia sobre la censura que se vivió bajo las dictaduras latinoamericanas y cómo se trató de esconder la tortura y la desaparición de personas ante los ojos del mundo entero. ${ }^{2}$

El restringir el acceso a la información acerca de los sucesos acaecidos en los campos de concentración es un ejercicio que va mucho más allá de querer mantener la credibilidad de sus prácticas al buscar manejar la interpretación misma del hecho histórico. Es decir, el poder político se sostiene sobre todo en la verdad del acontecimiento que se quiere perpetuar, y esta verdad se define en la interpretación que del mismo hecho histórico realice la sociedad. Como explica el mismo Todorov: "La idea de que es la voluntad del poder y no el conocimiento del objeto o el acuerdo universal de los hombres el que controla y orienta las interpretaciones es indispensable en la filosofía totalitaria: la verdad no es ya sino la consecuencia de esa voluntad" (2009: 262). En este sentido, pensamos los testimonios de prisión política como puntos de fuga que logran quebrar el totalitarismo de la información y generar distintas inflexiones a los modos en que han sido planteadas y juzgadas las

2 La forma en que se detenía a las personas acusadas de subversión era el secuestro, y su paradero inmediato no eran las cárceles formales, sino que centros clandestinos, como por ejemplo la ESMA o La Perla, entre otros, los cuales funcionaban en la total ilegalidad. Finalmente, los delitos de tortura y desaparición de los detenidos fueron de la misma manera ocultados, silenciados y negados durante mucho tiempo. 
catástrofes. Esto gracias a su potencial significativo arraigado en sus propiedades textuales, como lo ha demostrado Carolina Pizarro, quien considera el relato de prisión política como un texto portador de sentidos "no solo a través de los hechos que narra, sino especialmente de las formas escogidas por quien testimonia para dar cauce significativo a su experiencia" (2018:23). Esto implica comprenderlo "más que como un transmisor o vía de acceso expedita al referente, como un operador de estructuras narrativas, facultad que le permite dar contorno a situaciones extremas para la cuales la pura denotatividad del lenguaje no es nunca suficiente" (2018: 23). Por este sentido interpretativo de la historia que promueven los testimonios, unido a la clara intención literaria de muchos de ellos, es que consideramos fundamental consignar la posibilidad de un análisis de tipo hermenéutico a la textualidad testimonial.

Para acercarnos a la interpretación hermenéutica de un texto determinado, partimos de la base de que la cultura misma se organiza textualmente: "sus textos (escritos u orales, cifrados en uno y otro código) se presentan como las unidades complejas del entramado hermenéutico" (Cuesta Abad 1991: 138). En esta medida, hay que entender al testimonio como un elemento de la cultura que, si bien pertenece a un corpus específico de la post dictadura argentina, al mismo tiempo dialoga con una serie de otros textos pertenecientes a la tradición literaria de este país y del mundo y, por lo tanto, su interpretación debe conformarse tanto a partir del texto mismo como de su enlace con los demás textos, ya sean estos históricos, literarios, filosóficos, etc. Esto es lo que Cuesta Abad ha llamado el principio de "metatextualidad" propio del conocimiento cultural, mediante el cual cada texto "describe, analiza e interpreta las estructuras y el sentido de otros textos" (138).

Ahora bien, dentro de un panorama tan amplio, ¿cómo interpretamos, en código hermenéutico, un testimonio particular? Para ello hay que partir desde la unidad discursiva que constituye todo texto, concebido este como un ente orgánico, es decir, comprendiendo que "el escrito completo posee un significado a partir de sus enunciados o partes complementarias y [...] en la enunciación completa se detecta la tensión del sentido" (Ricoeur 1980:185). Todo texto tendría entonces una pluralidad de significados que, por un lado, solo se vuelven legibles en la interpretación del texto completo, esto es, a la luz de cada una de sus partes, y por otro lado, todo texto se entrelazaría a una red vastísima de otros textos de la cultura, delineados con menor o mayor especificidad formal en sus componentes discursivos. De este modo, para la interpretación hermenéutica es fundamental también determinar qué tipo de relaciones establece el texto en cuestión con otros textos incluidos formalmente en él, analizando los sentidos de estos diálogos y las distintas ilaciones con otras textualidades culturales específicas.

En esta línea, y llevándolo directamente al escenario del testimonio, una interpretación hermenéutica debe ir mucho más allá de la indagación de la veracidad o ficcionalización de lo relatado, para analizar todos los elementos discursivos que componen el texto testimonial, tratando de acotar ciertos rasgos formales que tensionen el sentido, para luego buscar aquellos modos en los que el testimonio se relaciona con otros textos culturales y los alcances hermenéuticos de estas conexiones. En el caso de nuestro trabajo, 
nos hemos concentrado en el análisis de ciertos elementos discursivos que nos resultan de sumo interés para la comprensión total de ambos testimonios, particularmente, me refiero a ciertas apropiaciones formales de la tradición literaria- como lo son el romance medieval y la novela de formación- que contribuyen ampliamente al significado de cada relato y que imprimen la experiencia traumática de nuevos sentidos, como intentaremos demostrar a continuación.

\section{Testimonio y Literatura: Estrategias de APropiación}

Entre los numerosos estudios sobre el testimonio argentino, destacamos el de Rosana Nofal quien se ha dedicado a investigar la particularidad de este género en tanto sistema de escritura diferenciable dentro de la literatura argentina. La autora lo concibe como "un modo particular de la escritura en la que se inscriben las memorias del pasado dictatorial y también las luchas por las identidades de ese pasado" (2010: 110). Para Nofal, el género testimonial argentino tiene como fecha de nacimiento el día en que Rodolfo Walsh escribe Carta abierta de un escritor a la Junta Militar. El asesinato del autor por parte de agentes de la ESMA al día siguiente del envío de este texto, termina por consagrar una imagen que pasa a la posteridad, determinando las identidades colectivas que se configuran en los relatos testimoniales del país vecino. Este movimiento de definición y proyección identitaria va de la mano con otro movimiento, que tiene que ver con la formalidad narrativa del testimonio argentino, en la medida que se constituyen los valores del militante como guerrero que resiste y muere por sus ideales. Los autores de testimonio relatan su experiencia desde una consigna cercana a la del periodista y desde una estética romántica, en todo lo que en este movimiento responde al motivo de la derrota. "La creación de héroes y demonios y la dificultad para hablar sobre los recuerdos será una constante en los testimonios” (Nofal 2010: 113).

Lo que nos resulta particularmente interesante es que la autora considere como fundamental la propiedad metafórica del testimonio, arraigada en una construcción escritural profundamente permeable a la ficción y sus retóricas (2010: 114). De acuerdo a su investigación, la identidad del militante se ampara en la figura del bandido como los nuevos héroes montoneros y, es esta figura protagónica la que, finalmente, genera la tensión del sentido hermenéutico y no la tan ampliamente estudiada fricción entre realidad y mundo ficcional. Desde esta lectura, los testimonios efectivamente tendrían una clara vinculación con formas estéticas determinadas, como lo serían en este caso el personaje del "bandido". En suma, Nofal utiliza otras categorías, además de las ya establecidas en el campo testimonial argentino, para estudiar los corpus, y de esta manera, poder leer en clave metafórica y literaria el testimonio. Estas categorías serán en términos de 'cuentos de guerra' con sus 'personajes', sus estereotipos, sus autofiguraciones 'heroicas' que se transmiten generacionalmente por los contadores de cuentos” (2015:849).

En una línea muy similar, la investigación de Pizarro (2018) postula un repertorio de géneros históricos que operarían como modelos de numerosos relatos testimoniales del 
Cono Sur, distinguiendo inicialmente entre "formas mítico/bíblicas", "formas medievales" y "formas modernas". Las primeras se relacionan "con interpretaciones de la prisión en clave épica o mesiánica, configurando un sentido fundante y/o trascendental para la experiencia" (39). En las segundas, "el problema del bien y del mal se encarna en estas estructuras en las disquisiciones respecto del buen o mal actuar de los sujetos ante las situaciones límite" (39), y en las terceras, el sentido histórico de la experiencia se aleja de lo trascendente y totalizante, para relacionarse con perspectivas parciales "que dan cuenta de la percepción fragmentada o de la incapacidad de explicación global para el estado de absoluta excepción de la prisión política" (39). Entre las formas mítico/bíblicas, Carolina Pizarro distingue la epopeya, el relato crístico y el apocalíptico. Entre las medievales se acotan la confesión, la imitatio Christi, y la hagiografía. Finalmente, entre las formas modernas aparecen la novela de formación, la novela de terror, el relato fantástico, la novela policial y el melodrama.

En relación a este estado del arte, proponemos que la apropiación de la retórica literaria que se observa en algunos corpus testimoniales, además de explicar hechos traumáticos e indagar en la identidad de los sujetos que padecieron del horror, es un mecanismo que permite reinterpretar el hecho histórico de alcance colectivo que encierra la experiencia de la catástrofe, a través de un ejercicio de construcción memorialística que irrumpe en la gran disputa por los sentidos de este pasado. A continuación, analizaremos dos ejemplos de testimonios en donde la interpretación del pasado histórico argentino se estructura en formas narrativas específicas que otorgan un contorno referencial y estético a la experiencia del trauma.

\subsection{La memoria que se canta. Una sola muerte numerosa de Nora Strejilevich.}

La autora Nora Strejilevich es una sobreviviente de la dictadura militar argentina en varios aspectos: padeció detención obligada y tortura en el centro Club Atlético en el año 1977, enfrentó la desaparición de su hermano Gerardo Strejilevich y de la novia de éste, Graciela Barroca e, inmediatamente después de su liberación, se exilia y transita por distintos países. Su testimonio - Una sola muerte numerosa- fue publicado en el año 1997 y es de común acuerdo para la crítica su originalidad y actualidad. Por ejemplo, Edurne Portela (2008) destaca que es un testimonio que no solo dialoga con aquellos pioneros de los ańos ochenta que se publican desde el exilio, ${ }^{3}$ sino que también con aquella literatura de exilio que no se relaciona directamente con el relato testimonial, como la literatura de Tomás Eloy Martínez o Juan Gelman, al incluir citas de ambos autores. Por otro lado, explica también Portela, que no se queda en la denuncia de los horrores de la dictadura, sino que además indaga "en el presente de la impunidad y del olvido oficial del pasado reciente" (Portela 2008: 2).

\footnotetext{
${ }^{3}$ Como Pasos bajo el agua de Alicia Kozameh (1986), Preso sin nombre, celda sin número de Jacobo Timerman (1981) o The Little School de Alicia Partnoy (1986).
} 
Otro aspecto del testimonio de Strejilevich que es muy referido es el de su literariedad que se consigue, según Fernando Reati (2004), gracias a una técnica narrativa de contrapunto que va situando en una constante oscilación una serie de imágenes, aparentemente inconexas de la época del horror y de su niñez. "Este vaivén se refuerza por medio de una técnica narrativa que consiste en vincular los sucesos pertenecientes a las épocas felices del 'antes' con el presente doloroso de la victimización, a través de asociaciones libres de palabras o imágenes que irrumpen en una especie de fluir de la conciencia de la narradora" (110). Estamos ante una escritura que goza de una recursividad literaria riquísima y que se nos presenta como una mixtura de géneros narrativos: novela, testimonio y autobiografía. Por otro lado, advertimos en su textualidad, además de la voz en primera persona que relata la experiencia carcelaria, numerosos insertos provenientes del discurso social que nos remiten a la época del horror argentino de la última dictadura, como por ejemplo: citas textuales de discursos oficiales a modo de epígrafes, notas de periódicos, cartas, poemas, canciones patrióticas, fragmentos del Nunca Más, otros testimonios, declaraciones de militares, entre otros. ${ }^{4}$ Tal como lo explica Nely Maldonado (2005), este testimonio posee un carácter heterogéneo, en el cual los fragmentos "no pretenden construir una historia individual, sino que aparecen como la posibilidad de registrar diversos relatos: las historias entrecruzadas, los caminos cercanos y destinos disímiles de muchos otros, conformando una suerte de biografía generacional" (2).

Se expresa así una clara vocación de memoria colectiva a través de recursos formales que nos van trasladando constantemente desde un "yo" a un "nosotros". "El yo es un nosotros (con)fundido en historias en las que se pierde toda identidad individual, en la que la identidad individual es inconmensurable con la colectiva" (Rodríguez 1998: 203). Dentro de esta panorámica que remite a una memoria social multivocal, hay un elemento que llama ampliamente nuestra atención y que es la utilización de pequeñas rimas infantiles y canciones populares como recurso literario. Es así como se puede observar una suerte de "repertorio cancioneril" que apela a la memoria colectiva del pueblo argentino de determinada generación. Si bien no son tan recurrentes ni mayoritarias, constituyen a nuestro juicio un punto nuclear para la interpretación hermenéutica de este testimonio, que es precisamente aquello que justificaremos a continuación.

En el primer párrafo de Una sola muerte numerosa, se relata de la siguiente manera la detención de la protagonista: "Tres pares de pies practican su dislocado zapateo sobre el suelo la ropa los libros un brazo una cadera un tobillo una mano. Mi cuerpo. Soy el trofeo de hoy. Cabeza vacía, ojos de vidrio. Los cazadores de juguete me pisan pisa pisuela color de ciruela" (1). La descripción narrativa de la experiencia de detención se descontinúa con lo que parece un paréntesis lírico que se conecta con el acontecimiento relatado, a partir de la asociación del verbo 'pisar', que relaciona el acto represivo de pisotear un cuerpo con el de esta rima infantil. ¿Pero es simplemente un asunto de relación sonora de palabras? En una entrevista concedida en el año 2014, Strejilevich explica esta recursividad de la siguiente manera:

${ }^{4}$ Esto ha sido calificado como un registro polifónico por María A. Semilla Durán, ver: Semilla Durán 2010: 142. 
Para mí esta experiencia límite no podía contarse como otras, requería un trabajo de figuración que usara otras estrategias. Inventé una textura que incorporaba hilachas de nuestro universo cultural, porque fue ese universo el secuestrado y amordazado por la dictadura: las canciones infantiles, filtradas por la atrocidad, la subrayaban e indicaban que el terror se ejerce en una sociedad que está educada para soportarlo. (2014).

Es así como esta rima sirve para subrayar el terror de la represión, desde una arista propiamente folklórica. No obstante lo anterior, consideramos que la inserción de rimas, rondas y canciones de la tradición popular argentina constituyen un recurso literario que, por un lado, y como bien explica la autora en la entrevista recién citada, acentúa con un eco cultural ciertos pasajes de la experiencia individual del trauma, y por otro -y aquí va nuestra hipótesis- es una estrategia narrativa de apropiación formal que permite situar, estructural y hermenéuticamente, la importancia de la transmisión de la memoria colectiva sobre un hecho histórico de relevancia, a través de la oralidad en sus más variadas modalidades. Es así como situamos este testimonio en una retórica muy cercana a los usos y formas de la tradición oral de la época medieval, en donde el registro oral fue el principal medio de difusión, incluso mucho después de la llegada de la imprenta, posterior a lo cual ciertos rasgos y mecanismos de la lírica y narrativa oral continuaron influyendo en la emergente producción de literatura escrita. ${ }^{5}$

En este sentido, consideramos que el testimonio de Strejilevich se apropia de ciertas estrategias y formas narrativas del 'romance' y algunos otros géneros marginales de la poesía medieval, como lo fueron las canciones, para atribuir un efecto lírico a la memoria colectiva de la época de dictadura, y con ello, resaltar el carácter compartido del recuerdo en su dimensión popular. En la Edad Media, las canciones eran poesías 'cantables' que poco a poco y ya avanzado el siglo XV, en su traspaso al manuscrito, fueron perdiendo su valor musical. ${ }^{6} \mathrm{El}$ romance, por su parte, fue el medio literario por excelencia que permitió la fijación de acontecimientos históricos, batallas, justas caballerescas, pero que también retrató relatos de vida, de amor y dolor, como ha quedado demostrado con los estudios de Di Steffano (1985) y Deyermond (2005), entre otros. Ambos géneros comparten ciertas formas y usos que dan cuenta de la importancia de la memoria, no solo para el oficio del trovador, sino que también para toda una comunidad que encontraba en estas prácticas distintas funciones.

\footnotetext{
${ }^{5}$ Como explica Alan Deyermond: "La oralidad influye en casi todos los géneros literarios que nos ofrece esta época de transición [...] A veces se trata de un género tradicional- oral en sus orígenes y hasta en su esencia- que se transforma en literatura escrita, como los romances y los refranes. A veces un género culto se oraliza, como la transmisión oral-memorial de los Proverbios morales de Sem Tob, o la composición oral de libros de caballerías" (2005: 45).

${ }^{6}$ Paradójicamente, a pesar que a mediados del siglo XV la canción había perdido el carácter musical, en el siglo XVI y en procesos de recopilaciones cancioneriles, se retomó este valor. Como se puede observar en el Cancionero de la Catedral de Segovia, Cancionero musical de la Colombina, Cancionero musical de Palacio, entre otros, que incluyen poesía lírica y villancicos que se cantaban en la corte (Deyermond 2005).
} 
Para ser más específicos, y entrar en un análisis más concreto, consideramos que las estrategias de la retórica pragmática y el fragmentismo, apuntadas por Diez Borque y Di Steffano, respectivamente, aparecen nítidamente en el testimonio de Strejilevich para subrayar la colectividad implicada en la memoria de dictadura. En primer lugar, la retórica pragmática, se define como los modos mediante los cuales el texto lírico contribuye a entablar una "relación con el trabajo, la búsqueda de algún tipo de practicidad, de rendimiento para la vida cotidiana, frente a una pura proclamación de literatura que se autojustifica en sí y por sí misma” (Diez Borque 1985: 49). En esta misma línea, para José María Díez (1985) este tipo de formas nacen y se mantienen sin vocación de literariedad, en cuanto que no pertenecen al margen de no-necesariedad inmediata que el hombre se otorga (ornatus), sino a una voluntad práctica de dominar la vida y provocar acontecimientos $(50)^{7}$. En relación a lo anterior, advertimos que las canciones insertadas en el testimonio de Strejilevich siempre funcionan como un intento por conjurar la memoria, es decir, para convocar la presencia de ciertos recuerdos.

Mientras manos anónimas nos palpan de armas, las mías revuelven sábanas de la memoria para despertar a los ausentes entre los pliegues. Ahí están, mis amigos: animados, como de costumbre. Con una zamba entre los dedos y la luna, arrimados a la nostalgia. Las canciones conviven con utopías paridas por la rabia (Strejilevich 2006: 98-99).

Se observa aquí la importancia atribuida a las canciones y la lírica popular en la medida que constituyen el medio a través del cual se consigue este conjuro de la memoria, que la autora convierte en toda una poética del recuerdo, traspasando el mero placer estético para alcanzar un objetivo concreto, que sería en este caso, plasmar la memoria, retratar fragmentos de una época y una generación.

El fragmentismo, por su parte, alude a la propiedad romanceril de mencionar retazos de vida, sin pretensiones de totalidad que indaguen en el origen primario de los acontecimientos, ni mucho menos que procuren establecer finales totalizantes (cit. en Díez Borque 1985: 51). Esto se observa en toda la obra, la que en su conjunto, como ya se ha acotado, es un abanico de pequeños relatos con distintos protagonistas, pero con un factor común: haber vivido ese período. Por ejemplo, en el apartado titulado "Esa condena", el relato se detiene en la madre de la protagonista a partir de un collage de canciones: trozos de tangos y boleros que recrean la imagen de la madre cantando mientras se dedica a los quehaceres domésticos. Se cita canciones como "Vagabundo" (Los Panchos), "No nos veremos más” (Lucio Demare), "El cambalache” (Carlos Gardel), entre otros, para finalizar el repertorio con una reflexión sobre la vida de la madre, pero que expande una resonancia

\footnotetext{
${ }^{7}$ Las canciones aparecen también en textos medievales en prosa, como por ejemplo, en La cárcel de amor de Nicolás Nuñez (continuación de la obra de Diego de San Pedro) tenía 25 poemas, 1 canción y un 1 villancico (Deyermond 2005).
} 
hacia toda una colectividad: "Puede que cantar con voz rotunda y saltarina sea un modo de sacarle brillo a tu modesta rutina, que cumplís a regañadientes en tu jaula de oro" (35).

En definitiva, el texto de Strejilevich consigue evocar la época de dictadura a través de la utilización constante pero fragmentaria del lirismo cancioneril y popular de este período, en un gesto formal que nos remite a la utilización pragmática de la literatura oral para evocar el pasado, propio de la edad medieval, época que dependió mucho de la memoria, tanto en términos prácticos como recreativos, y en la cual la historia de los héroes y la memoria colectiva se cantaron y difundieron popularmente, durante mucho tiempo.

\subsection{Coordenadas sociales en el discurso intimista de Sueños sobrevivientes de una montonera, de Susana Jorgelina Ramus ${ }^{8}$}

Aparecido en el año 2000, el testimonio Sueñossobrevivientes de una montonera. A pesar de la ESMA de Susana Jorgelina Ramus es presentado por el prologuista Horacio González como un relato profundamente intimista, describiéndolo a través de la siguiente imagen: "Diario íntimo, monólogo amoroso de señorita que llena cuartillas un tanto ruborizada, jugando con la deliciosa impudicia de una confesión" (2000: 7). ${ }^{9}$ En este testimonio el discurso intimista es una constante de ilación textual, que va hilvanando las memorias de la sobreviviente a partir de la escritura en primera persona, no obstante, lo cierto es que el relato delimita asimismo un contexto social visible y presente, que se formaliza en el relato del compromiso militante de Montoneros: "Creíamos que teníamos que anunciar el mundo futuro" (Ramus, 2000:11); y de la victimización de los sobrevivientes: "Nosotros somos las víctimas, ellos los verdugos" (Ramus 2000: 30). En ambas instancias en donde la voz del "yo" se incluye en un "nosotros" comunitario que se pretende definir identitariamente. Para instalar el discurso social y complementar el "yo intimista" se observan, además de un cambio en el registro narrativo, la inserción de reseñas históricas de montoneros, cartas dirigidas a detenidos desaparecidos o familiares, comentarios de noticias de la época, relatos de la ESMA, fotografías, entre otros. De este modo, el testimonio de Ramus excede la intención referencial y de denuncia, al ir más allá que relatar su detención y tortura, para avanzar en un relato biográfico de índole reflexivo que se extiende desde su niñez, pasando por la militancia, reclusión, exilio en 1979, hasta llegar a la actualidad, a través de una narración discontinua y no-cronológica. En este recorrido aparentemente desorganizado, advertimos la búsqueda de las relaciones que podrían enlazar los distintos episodios de su vida, entendiéndolos desde el presente de enunciación. Es así como la narración asume la forma de un rompecabezas biográfico que intenta armarse a través de la escritura, y mientras

\footnotetext{
${ }^{8}$ Susana Jorgelina Ramus fue secuestrada en el año 1977, detenida y torturada en la ESMA, y posteriormente exiliada en el año 1979. Militó en Montoneros desde muy cerca, al ser hermana de Gustavo Ramus y novia de Mario Firmenich, fundadores de este movimiento.

9 Más adelante, lo califica de "epístola introspectiva" y "carta escrita para sí mismo" (8). Estas citas corresponden al prólogo del testimonio de Ramus (7-8).
} 
se pretende contar este yo íntimo, lo social se va insertando a modo de intertextos necesarios para ejercitar la memoria de una época.

Al observar la preponderancia de la tensión entre el motivo identitario y el peso de la contingencia histórica de la época, en la escritura del yo testimoniante nos resulta plausible asociar, más que un "diario íntimo" o "carta confesional", la forma narrativa moderna del bildungsroman o novela de formación, que incluye este tipo de recursos narrativos en una estructura de sentido mayor. Las novelas de formación nos cuentan la vida de un personaje, su período de crecimiento y búsqueda identitaria en un contexto socio-cultural especificado en la narración: "Los relatos tienen un doble carácter, biográfico y social, y en ellos la sociedad es el eje antagónico. La trama consiste en la búsqueda gradual del individuo hasta llegar a desarrollar un sentido de su propio yo. La novela no es una biografía completa, sino la historia de un aprendizaje" (Lagos 1996: 34).

Es importante destacar que, en el caso de las novelas con protagonista femenino, estamos frente a un proceso de crecimiento variante que va dependiendo de la coyuntura histórica y de las condiciones socio-culturales de una época (Gómez 2009). De este modo, en el caso de las heroínas y sus caminos de realización, es mucho más viable observar los mecanismos represivos impuestos por el sistema genérico prevaleciente en las sociedades representadas, porque allí es donde se pone el acento. En este sentido, Zulema Moret (2008) advierte que las novelas de formación con protagonista femenino se centran en la construcción del sujeto mujer y su diferencia, y en esta construcción se observa un individuo anulado en términos de sus deseos y añoranzas de realización, y es por ello que necesita recuperar esa voz silenciada por la historia oficial (cit. en González 2010: 206).

Son novelas que además cuestionan lo que significa ser mujer en la sociedad, en un momento de particular contingencia, como lo sería en este caso, la represión de Estado. El cruce o enfrentamiento entre memoria colectiva e individual es fundamental para comprender los procesos identitarios que enfrentan las protagonistas de una novela de este estilo. Hay que destacar que este es un género que fue muy utilizado por las narradoras latinoamericanas de finales del siglo XX, por lo tanto, en la época de dictaduras del Cono sur, esta forma escritural estaba muy en boga y constituyó un vehículo literario para expresar las dificultades identitarias y de realización personal de muchas protagonistas producidas entre 1930 y 2000 , aproximadamente. ${ }^{10}$

$\mathrm{Al}$ analizar el testimonio de Ramus como un testimonio escrito bajo el alero formal del bildungsroman, notamos que son dos aspectos los que van delineando su identidad en pos de su constitución como sujeto moral, que son, como mencionamos previamente, ser mujer y ser sobreviviente. El ser mujer parece no coincidir con la moralidad contemporánea en tanto para ella fue equivalente a ser madre-militante, madre-prisionera y madre-exiliada. Ramus se detiene insistentemente en rememorar su maternidad mientras militaba, y luego en

\footnotetext{
${ }^{10}$ En estos corpus se distinguen novelas como: La casa del ángel (Beatriz Guido, 1954); Nada que ver con otra historia (Griselda Gambaro, 1972); Las ceremonias del verano (Marta Traba, 1966); La flor de Lis (Elena Poniatowska, 1988); Óxido de Carmen (Ana María del Río, 1986), entre otras.
} 
su posterior arresto que conllevó su propia ausencia en la vida de su pequeña hija, haciendo el respectivo mea culpa: "Un día que se va otro que viene y otro más, mi dulce bebé, cómo vivir sin verte, sin contarte cuentos a la noche, hacerte pasar por ese dolor, nunca voy a perdonármelo" (70; cursivas en el original). En relación a su sobrevivencia, a pesar que la autora se niega a brindarle autoridad a quienes la juzgan por sobrevivir - “ [...] en esa situación era imposible elegir, o por qué cada uno hacía lo que podía. Y quién puede juzgar. El que pueda que tire la primera piedra. Sé que algunos creen que pueden. Pero gracias a Dios no han vivido esa experiencia" (53)- lo cierto es que los modos de narrar el trauma dejan entrever cuánto de afectación y menoscabo quiere remediar su autora: "no es mi culpa haber sobrevivido/ es terriblemente doloroso serlo pero tengo que cargar con eso y seguir adelante/ por eso cuando alguien me dice que está podrido de los nostálgicos de los 70 no digo nada” (88). No obstante el yo testimonial procure ignorar este discurso y asumirse como víctima, lo que observamos es una discursividad narrativa de rendición de cuentas, que indaga en su inserción en la sociedad en código biográfico amplio y no sólo como relato de su experiencia carcelaria, utilizando principalmente las formas del diario de vida y de la carta confesional. ${ }^{11}$

En atención a lo anterior, postulamos que el testimonio de Ramus se ampara en ciertos mecanismos de la novela de formación femenina- como lo son la confesión, la carta introspectiva o el diario de vida- para otorgarle determinados significados a su experiencia traumática, los que están dados por la estructura narrativa principal de este género, que es el de la tensión entre definición identitaria de la protagonista y momento socio-cultural que la rodea y que cumple el rol de antagonista. En Sueños sobrevivientes de una montonera, la mujer militante se enfrenta a una cultura patriarcal/dictatorial que la juzga por ser mujer y por ser sobreviviente de prisión política, y ambos factores son los hilos conductores de cada fragmento del testimonio de Ramus. En este sentido, consideramos que el afán de reconocimiento identificado en el testimonio se debe a un sentimiento de no-pertenencia con el mundo social que la rodea, no por ser un 'sujeto traumatizado' que no ha podido elaborar su experiencia, sino que a causa de su condición de sujeto moral cuestionado. Es por ello que indaga en su vida buscando argumentos que la convenzan a sí misma y a otros que todo lo realizado como militante fue por un bien superior, y lo que hizo dentro de la ESMA fue nada más que lo que pudo: "Debo perdonarme, debo ser un poco más indulgente conmigo porque no está bien juzgarme ahora desde este lado, saber que hice lo que pude y que no tenía opciones, que estaba a merced de otras personas y que ya todo ese horror pasó y que sólo fui una víctima” (88).

Hay un aspecto que puede resultar contradictorio con el término de "novela de formación personal" en el caso del testimonio de Ramus y es el que se refiere al tono de

\footnotetext{
${ }^{11}$ El diario de vida es mencionado concretamente como soporte original de lo relatado: "Ahora que al fin he podido reconciliarme conmigo la perspectiva es diferente. No sé cómo llegué a este momento, los recuerdos del pasado son de mucho sufrimiento, cuando veo mi diario veo cuanto me costó llegar a sentir esto" (Ramus 2000: 69-70). Mientras que las cartas confesionales son insertadas de manera intercalada en el testimonio, y contribuyen a engrosar las distintas dimensiones de la experiencia traumática. Se advierte, por ejemplo, cartas a su hermano Carlos.
} 
frustración y resignación que inunda todo el texto y que, opuesto al motivo de soslayar escollos para llegar a buen puerto, como es el caso de muchos ejemplares de este género, la obra de Ramus expone más bien lo que sucede cuando, finalmente, nada de lo deseado por la protagonista se concreta. Como es posible especular, esto no es tan lejano a ciertas tramas que desarrollan las novelas de formación femenina, por la condición antagónica que sitúa a la protagonista versus la sociedad patriarcal, tanto es así que la crítica especializada las ha particularizado en la denominación Failed Bildungsroman, que serían aquellas novelas que muestran un desvío de la norma "educativa" propia de este tipo de narrativas, es decir, que el aprendizaje como valor rige la vida de la heroína, lo que hace variar al género clásico. Una "novela de formación fracasada" se da cuando las protagonistas no tienen éxito en su autorrealización y, por el contrario, tienen un desenlace de frustración, muerte y/o sacrificio. ${ }^{12}$ En el testimonio de Ramus, podemos observar que se produce este tono de frustración ante la no consecución de los sueños que la motivaban en su juventud, a ella y a toda una generación. Unido esto al estado político del momento de enunciación de la testimoniante, es decir, un consolidado sistema neoliberal, el fracaso se vuelve mucho más definitivo. En la siguiente cita se destaca, justamente, el principal rasgo del bildungsroman fracasado, que es el de la no integración del sujeto en la sociedad.

Por qué estamos todos tan tristes, sí, es cierto que ya no funciona nada de lo que creíamos o esperábamos, vos tenés razón, pero entonces qué hacemos, cómo no caer todo el tiempo en la tristeza o la melancolía o la nostalgia, será ese fin de las utopías lo que nos mató, o esta globalización, o sentir que la patria no existe y no hay por qué luchar/ hasta los proyectos personales salen mal, no solo los nuestros, también los de los amigos (Ramus 2000: 51).

La ironía es una de las estrategias narrativas del bildungsrroman clásico, en donde la distancia entre el yo adolescente y el yo maduro se contraponen a través de este recurso, para subrayar la inocencia, ingenuidad e inexperiencia del yo anterior, contraponiendo los sueños con la realidad. Para muchos críticos, la ironía cumple una función estructural en las novelas de formación, y estaría dada por una "mediación que solo permite alcanzar la verdadera naturaleza de la obra por una vía indirecta” (Escudero Prieto 2008: 13). En el caso del testimonio de Ramus, nos encontramos ante una ironía nostálgica que constantemente pone en perspectiva el desencanto de una generación militante, a través de la contraposición

\footnotetext{
${ }^{12}$ La denominación de Failed Bildungsroman fue bastante polémica dentro de la crítica especializada. El debate apuntaba a qué entendemos por fracaso y si este sería una característica exclusiva de las novelas de autoría femenina. Para un sector, el fracaso corresponde a no conseguir el éxito en la realización, y para otro, el éxito mismo refiere a una ruta trazada por el patriarcado, por lo tanto, no es viable como parámetro de evaluación de las novelas de formación femenina, las que justamente buscan develar dicho patrón y su influencia en la vida de las mujeres. Hoy en día, como explica Gómez Viu "se reconoce que no todos los bildungsroman masculinos concluyen con un final armonioso, por ello la crítica reciente ha subrayado la incertidumbre de muchas novelas de formación" (2009: 110).
} 
entre lo que se esperaba y lo que terminó siendo el país argentino luego de la dictadura, destacando así también la inocencia e ingenuidad de sí misma y del grupo.

La vida era una fiesta, todos los días nos encontrábamos para crear, para pensar en cómo modificar esto o aquello, para que las carreras de la Facu fueran buenas, para que en los barrios y en las fábricas la gente se organizara y consiguiera lo que necesitaba [...] Ahora después de tanto tiempo, puedo decir que todo esto ya es pasado [...] Pienso que este es un mundo terrible [...] nosotros queríamos soluciones más definitivas, pero no pudimos y no tiene sentido pensar ahora qué o la revolución o nada $(40)$.

Finalmente, existe en el testimonio de Ramus otro rasgo particular de la forma del bildungsroman que podemos destacar y es la presencia de un "educador", personaje prototípico que aparece en la trama con el rol de cooperar en el proceso de formación del protagonista. Este personaje cumple un papel fundamental en el camino de aprendizaje al funcionar como mediador entre la sociedad y el héroe, y se emparenta con "El Caballero" de la literatura espańola medieval, en particular de las novelas caballerescas y de las poesías de trovadores del medioevo, y también a los "caballeros" del teatro del Siglo de Oro (cit. en Melgar 2012: 73). Debemos agregar que este personaje es igualmente similar en ciertos rasgos a los "maestros" del pícaro del siglo de oro español, que ayudaban a este personaje en su travesía a buen puerto. La apropiación de esta forma narrativa en las novelas de formación femenina en muchos casos desempeńa un papel contraproducente con el aprendizaje de las heroínas, como lo ha demostrado la crítica en ciertas obras de Carmen Boullosa y Sandra Cisneros, entre otras. ${ }^{13}$ Esto debido a que el "educador" pretende normar y educar al sujeto femenino en clave patriarcal, lo que conlleva a la no consecución de una identidad propia en las heroínas. En el caso de Sueños sobrevivientes se observa claramente cómo la protagonista destaca el rol formador que cumplió su hermano en términos ideológicos y personales. La narración en primera persona cuenta que ingresó a Montoneros porque lo admiraba y porque éste pensaba que era lo correcto hacer. Además siente que le ha fallado al no haber estudiado lo que éste le sugirió, danza o teatro. Es tan fuerte el rol de "mediador" que retrata Ramus para su hermano, que la muerte de éste es apuntada como la causa de la pérdida del rumbo: "Siento que estoy huérfana desde los veinte ańos y no fue justo que te hayan matado a vos que eras el bueno de Roy Rogers y yo Mar Rosen el malo, pero no tanto, y nos queríamos mucho y mi mundo se derrumbó y anduve por ahí sin saber qué hacer y todavía no lo sé” (54).

En relación a lo anterior, es importante aclarar que no estamos postulando que las apreciaciones y sentimientos de Susana Jorgelina Ramus respecto de su hermano sean ficticias, sino que por el contrario, en la escritura testimonial dichas valoraciones personales

\footnotetext{
${ }^{13}$ De Carmen Boullosa se han analizado en este sentido Mejor desaparece, Antes y Treinta años, y de Cisneros The house of Mango Street y Caramelo. Ver: "Los bildungsroman femeninos de Carmen Boullosa y Sandra Cisneros: mexicanidades, fronteras, puentes" (Melgar, 2012).
} 
y filiales han adquirido una forma narrativa de larga data en el canon literario occidental, y que le han servido a la autora para expresar su experiencia.

\section{Conclusiones}

Los testimonios de Strejilevich y Ramus no solamente dan cuenta de su trauma y de cuánto afectó sus vidas la catástrofe política argentina, sino que además procuran incorporar los sentidos de la experiencia individual en la colectiva, alcanzando una definida dimensión histórica. Esto se consigue a través de distintos mecanismos de apropiación literaria plasmados en la formalidad de ambos testimonios. Es así como podemos observar la presencia de ciertos rasgos del romance y los cancioneros medievales, ambos géneros fundamentales en la transmisión de la cultura popular y la memoria colectiva mediante el registro oral y las estrategias literarias propias de este estilo. Por ello es que no es azarosa su inclusión, así como tampoco lo es la de ciertas estrategias de la novela de formación, en su calidad de ficciones que desestabilizan las memorias hegemónicas de una cultura determinada, a partir de la narración de un individuo y sus vicisitudes en la sociedad, en un momento particular de crisis y adversidad política. Estas novelas consiguen evidenciar cómo el campo de lo público es indisoluble del privado, y develar cómo esta encrucijada definitivamente asalta y delinea las identidades individuales. Específicamente, los bildungsroman de protagonista femenino constatan lo difícil que ha sido para las mujeres elevar su voz, y por ello irrumpen e interrumpen con tal fuerza en el imaginario colectivo de las memorias sociales.

Finalmente, todo texto tiene un significado múltiple y, tal como postula Paul Ricoeur, "es en la interpretación donde la pluralidad se pone de manifiesto" (2003: 17). De esta manera, es gracias a la interpretación hermenéutica de ambos testimonios que emerge la importancia de las formas narrativas de las que se apropian estos relatos de prisión política y se supera el sentido referencial y subjetivo del trauma, para proyectar una re-interpretación del fenómeno histórico en el cual inscriben sus identidades.

\section{OBRas Citadas}

Andradi, Esther. 2014. "Narrar para resistir. Entrevista con Nora Strejilevich". La Jornada, Suplemento Cultural.

Cuesta Abad, José Manuel. 1991. Teoría hermenéutica y literatura. El sujeto del texto. Madrid: Visor.

Deyermond, Alan. 2005. "La literatura oral en la transición de la Edad Media al Renacimiento”. Acta Poética 26: 29-50.

Díez Borque, José María. 1985. "Conjuros, oraciones y ensalmos: formas marginales de poesía oral en los siglos de oro”. Bulletin Hispanique 87, 1: 47-87.

Escudero Prieto, Víctor. 2008. "Reflexiones sobre el sujeto en el primer Bildungsroman". 
Trabajo de investigación. Nora Catelli, dir. Barcelona: Universitat de Barcelona.

Gómez, Carmen. 2009. "El bildungsroman y la novela de formación femenina hispanoamericana contemporánea”. Epos 25: 107-117.

González, Horacio. 2000. Prólogo. Sueños sobrevivientes de una montonera. A pesar de la ESMA. Por Susana Jorgelina Ramus. Buenos Aires: Ediciones Colihue. 7-8.

González, María Virginia. 2010. Res. de "Esas niñas cuando crecen, ¿dónde van a parar" por Zulema Moret. Amsterdam-NewYork: Rodopi, Anclajes 14: 206-208.

Lagos, María Inés. 1996. En tono mayor. Relatos de formación protagonista femenina en Hispanoamérica. Santiago: Cuarto Propio.

Link, Daniel. 2008. "Qué se yo. Testimonio, experiencia y subjetividad”. En Vallina, Cecilia (edit.) Critica del testimonio. Ensayos sobre las relaciones entre memoria y relato. Rosario: Beatriz Viterbo. 118-131.

Maldonado, Nely. 2005. "Identidad, memoria y escritura: Una sola muerte numerosa de Nora Strejilevich". Ponencia. Coloquio Dis/location: Writing exile/Migrancy/Nomadism/Bordercrossing. Concordia University, Canadá. Recuperado en: https://www. academia.edu/673936/Identidad_memoria_y_escritura_Una_sola_muerte_numerosa_de_Nora_Strejilevich 15 de May.2017.

Melgar, Yolanda. 2012. Los bildungsroman femeninos de Carmen Boullosa y Sandra Cisneros: mexicanidades, fronteras, puentes. Tamesis: London.

Nofal, Rossana. 2010. "Operación masacre: la fundación mitológica del testimonio". Kipus. Revista Andina de Letras 28: 109-131.

Pizarro, Carolina. 2018. "Formas narrativas del testimonio". Donde no habite el olvido. Herencia y transmisión del testimonio en Chile. Milán: Di/Segni. 21-42.

Portela, M. Edurne. 2008. "Cicatrices del trauma: cuerpo, exilio y memoria en Una sola muerte numerosa de Nora Strejilevich". Revista Iberoamericana 74, 222: 1-14.

Ramus, Susana Jorgelina. 2000. Sueños sobrevivientes de una montonera. A pesar de la ESMA. Buenos Aires: Ediciones Colihue.

Reati, Fernando. 2004. "Trauma, duelo y derrota en las novelas de ex presos de la Guerra Sucia argentina”. Chasqui. Revista de Literatura Latinoamericana 33, 1: 106-127.

Ricoeur, Paul. 1980. La metáfora viva. Madrid: Europa.

2003. El conflicto de las interpretaciones. Ensayos de hermenéutica filosófica. Buenos Aires: Fondo de Cultura Económica.

Rodríguez, Ileana. 1998. "Res. de "Una sola muerte numerosa” por Nora Strejilevich". Letras Femeninas 24, 1: 203-206.

Semilla Durán, María A. 2010. "El cuerpo convulso de la escritura: Una sola muerte numerosa de Nora Strejilevich”. En González, Cecilia et al., eds., Las armas y las letras. La violencia politica en la cultura rioplatense desde los años 60 hasta nuestros días. Bordeaux: Presses Univ. De Bordeaux. 137-152.

Strejilevich, Nora. 2006. Una sola muerte numerosa. $2^{\circ}$ Ed. Córdoba: Alción.

Todorov, Tzvetan. 2009. Frente al límite. México: Siglo XXI Editores. 
